\title{
HIGHER EDUCATION REFORMS, EMPLOYABILITY, AND LABOR MARKET PARTICIPATION OF WOMEN GRADUATES: A CASE STUDY ON PUNJAB PROVINCE (PAKISTAN)
}

\author{
Muhammad Wajid Tahir \\ Research Fellow \\ Politics \& Gender Relations \\ Philipps University Marburg, Germany \\ muhammad.tahir@staff.uni-marburg.de, \\ wajidtahir@daad-alumni.de \\ Rubina Kauser \\ rbn_kauser318@yahoo.com
}

\begin{abstract}
It is presumed that access to higher education helps improve the chances of women to participate in the labor market after graduating from Pakistani universities. However, it is not a linear process because several other factors mediate this relationship. One of the other factors is improved 'employability' of graduates. To improve the 'employability' of students, the government has introduced several reforms in the Higher Education sector since 2002. Particularly, the annual examination system has gradually been converted to a semester system. The new system offers several opportunities to students to improve their 'employability' during their studies. Although several factors determine 'employability' of university graduates, the current study predicts 'employability' of women graduates through eight predictors using logistic regression analysis. Quantitative data is collected through a structured questionnaire. Findings reveal that an improved higher education level (e.g. double degrees, research degrees, PhD), the study of subjects from the disciplines of 'science \& technology', and outstanding academic grades can increase women's chances to enter the labor market if a gender-sensitive legal framework also regulates the labor market.
\end{abstract}

Keywords: educational patterns, employability, women graduates, universities, labor market

\section{INTRODUCTION}

Can higher education sprawl alter traditional gendered composition in the labor market of Pakistan? From the global perspective, a significant increase in women's enrolment at universities has been taking place across the world. A report by UNESCO (2020) informs that more women than men graduated from higher education across the world. Although this is a welcome change in the traditional dynamics of gender equality, there is another serious concern, which invites special attention. If gender-egalitarian change has been observed at universities, and women are inflowing towards higher education at a faster pace in comparison to previous years, then why do they fail in chasing their counterparts in labor markets? There can be numerous explanations of this paradox, but Inglehart and Norris (2003) assert that women's entry and empowerment at workplaces is closely associated with a change in their educational patterns $(\mathrm{P}, 30)$. Thus, it is presumed that only growing enrolment at universities is not enough to guarantee their employment after graduation. Labor markets seek human capital with specialized skill sets, which advantages candidates with requisite skills. It is interesting to probe if female students improve their 'employability' during their stay at universities in Pakistan.

It is presumed that universities will provide all possible opportunities to their students for improving their 'employability' so that they could qualify as potential candidates for employment after graduation. Nevertheless, prevailing literature explains the situation in two different dimensions. On the one hand, growing access to higher education is changing the traditional status of women in societies, e.g., improved autonomy, reduced cultural stereotypes, enlarged circle of choices, increased familial wellbeing, enhanced eligibility for competitive jobs, reconciliation in professional and family responsibilities, and improved self-confidence (Khan and Khan, 2009; Stier and Yaish, 2008). On the other hand, literature also asserts that transition from higher education to employment is not a linear 
process, because alone graduation from universities cannot guarantee women's entry into the labor market (Morley, 2010; Nelson, 2004). Although an elevated level of education has empowered them partially, their credentials are less valued than the degrees of men in recruitment processes. In many cases, families do not envisage their qualifications as instruments of 'breadwinning' tools and employers do not perceive them as reliable partners - due to anticipated reproductive interruptions for advancing professional careers (Das, 2006). These disparities have led to serious concerns about the expansion of higher education opportunities to women. In such circumstances, the entry of women at universities will be futile, if graduates cannot find appropriate employment opportunities following higher studies.

In the case of Pakistan, a visible change in women's enrollment at universities has been noticed after 2002 when the government has given a mandate for expansion of universities to the Higher Education Commission (HEC). New higher education vision encompasses commencement of new universities, the establishment of sub-campuses, revision of education system (from annual to semester), teacher to a student-centered approach, and industry-academia linkages (promoting internships, research projects, training, etc.). The subsequent governments have continued to support similar initiatives before and after the $18^{\text {th }}$ constitutional amendment. Historically, most women had a lack of space at higher education institutions, but new initiatives have benefited women plausibly (British Council, 2014). Nevertheless, like many other countries, Pakistan is also experiencing a paradox in the cases of educational and economic empowerment of women, which is affecting poverty reduction strategies adopted by the state. Thus, it is astonishing if women are entering universities by challenging cultural and religious stereotypes in comparison to the past, why they could not remove barriers to their employment in Pakistan? There can be several explanations of this mismatch, e.g., cultural norms and values, patriarchal religious doctrine, and biased legal frameworks, but a very conventional argument is that the labor market prefers graduates with improved 'employability' (Buchmann \& DiPrete, 2006), which is determined by 'educational patterns" (Mandel \& Shalev, 2009). Thus, this study attempts to find an association between 'educational patterns' and labor market participation of women who graduated from universities in Pakistan.

\section{CONCEPTUAL FRAMEWORK}

The study has been designed by combining the concepts of 'educational segregation', 'learning mechanisms', and 'employability' that exert a strong influence on women's inclusion in the labor market. First, women and men select different 'subjects' that ends up with gender-specific professions. Second, the labor market communicates gender-biased signals based on women and men choose special 'learning mechanisms' during studies. Third, the former and latter concepts (processes) determine women's 'employability' after graduation.

On the one hand, the 'educational segregation' is deeply prevalent in societies, which socializes women and men to comply with acceptable 'masculine' or 'feminine' dichotomies (Shah, 2010). Often women are stressed to study 'traditional-female' disciplines so that they could learn behaviors and skills complying with culturally acceptable roles (Leathwood, 2005). Although today women are marching towards subjects that are usually perceived as 'manly', e.g., 'mathematics and science', their pace is lethargic because they face two stereotypes from childhood, i.e., women cannot perform well in mathematics, and the work in sciences better suits to men (Hill, Corbett, \& St Rose, 2010). Literature also infers that although women perform better than their counterparts in academics, gender stereotypes are deeply entrenched in their brains, thus neither they recognize their abilities nor pursue 'market-oriented' subjects (Kumar \& Debjani, 2013).

On the other hand, the scholarship also implies that the return of education is associated with ability. The abilities of graduates cannot be measured solely based on years of education, but there is specific 'learning mechanisms' that shape their competencies and enhance their suitability for future employment (Hannum \& Buchmann, 2005). Ayalon (2003), associates attempt of women to adopt special 'learning measures' during studies with anticipated gender discrimination in the labor market. Prevailing incidents of gender-based discrimination at workplaces coerce women to study genderspecific 'subjects' and to prefer gender-specific 'learning mechanisms' so that they could join the relatively less discriminatory segments of the labor market. According to Mandel and Shalev (2009), both women and men choose to learn paths in anticipation of their future roles and responsibilities and

\footnotetext{
${ }^{1}$ educational choices and learning mechanisms
} 
expected returns to education. Both the society and the labor market prioritize one gender over the other for 'breadwinner' roles. Hence, 'learning mechanisms' are also prioritized based on gender putting women into situations/processes that end up with restricted 'employability', e.g., unemployment or induction in 'female dominant' sectors (Stanfors, 2006).

Bebbington (2002) accentuates to address the issue of women's under-representation in specific disciplines and lack of involvement in additional 'learning mechanisms' that can negatively affect their 'employability' through comprehensive public policies. In the case of Pakistan, the HEC has introduced various reforms to minimize gender gaps in academics, but it is not clear to what extent these measures have brought changes in the attitude of female students towards improving their 'employability'. It is presumed that if enrolment composition has been changing at universities, it will also challenge gender-based 'educational segregation' and enable women to more concentrate on special 'learning mechanisms' so that they could improve their 'employability' during studies.

The study operationalizes 'educational segregation' as if women still study subjects from 'social sciences, arts \& humanities', and avoid subjects from 'science \& technology' preferably, and 'learning mechanisms' as if women study under the semester system, participate in co-curricular activities (internships, research projects, training, etc.), and achieve above-average grades in last degrees, and 'employability' as if women find job-offer or do jobs in the labor market after graduation. The study will underline to what extent 'educational patterns' - 'subject selection' and 'learning mechanisms' - shape women's 'employability' and determine their entry into the labor market before establishing a straight relationship with educational attainment and labor market participation. The following hypotheses are tested with empirical data:

1. HEC's policies have altered the academic culture at universities; the new culture has introduced new learning mechanisms that can help women improve their 'employability'.

2. Improved 'employability' facilitates women's entry into the labor market after graduation.

\section{REVIEW OF LITERATURE}

Existing literature sheds light on factors that can enhance or reduce the 'employability' of university graduates. It has been noticed that the process of 'academic learning' is not free from gender bias. Although universities have a significant proportion of female students, academic divisions and related processes do not completely dispose of gender stereotypes. Most women graduate from universities with skills and credentials that are relatively less likely to be sought by employers (Leuze, 2010). Although it cannot be generalized, the subjects of 'science \& technology' are more likely perceived as 'market-oriented' than the subjects of 'social sciences, arts \& humanities' across the world (Gareth \& Chant, 2009). In the past, women had a lower inclination toward 'market oriented' education. Hence, they had been studying traditionally defined female subjects (Estavez Abe, 2006). The 'choice of the subject' does not depart from the notion of 'traditional division of labor'. From early stages in life, women are encouraged, either by their families or society, to perform caregiving roles in their lives, thus they are guided to focus on 'traditional-female' subjects, whereas men, because of their historical breadwinner roles, are encouraged to study 'market-oriented' subjects (Porter \& Umbach, 2006). In the case of Pakistan, the Pakistan Council of Science \& Technology cites statistics from UNESCO (2015) and elaborates that 37 percent women researchers are attached to medical science, 38.8 percent are attached to natural sciences, 15.4 percent are linked to engineering and technology, 11 percent are working in agriculture sciences, and 40 percent are part of social sciences and humanities. Hence, they are under-represented in the relevant sections of the labor market.

The national education systems and labor markets are closely connected aiming to produce a high-quality human resource to fill emerging market demands. If the supply and demand relationship remain consistent, it expedites a graduate's transition from educational institutions to the workplace; otherwise, it can obstruct it (Leuze, 2010). The higher education reforms in the country have been taking place since the inauguration of HEC. Relevant initiatives intend to improve the quality of graduates at par with international standards so that they could compete in global markets conveniently (Parveen, et. al., 2011). In this context, harmonization of the education system in the lines with internationally acceptable standards is a major step. Literature refers to two types of examination systems in the country: annual and semester (Khattak et al., 2011). Both systems have various advantages and disadvantages for students. In the annual system, the students take an examination once a year. The system supports traditional teaching and learning methods. Learning patterns are based on the repetition of material and do not offer additional learning activities. 
Examination papers are prepared and evaluated by external teachers (Yousaf \& Hashim, 2012). On the flipside, the semester system comprises two six-month terms, examinations occur at the end of each term. A teacher defines course outlines, set paper schedules, and compile results. The system has been designed on a 'student-centered' approach that focuses on self-learning and advanced learning methods and techniques. Students are evaluated during the term through class assignments, quizzes, presentations, mid-term, and final-term examinations (Aslam, et al., 2012; Jadoon, Jabeen \& Zeba, 2012). Apparently, it seems that education and learning under the semester system is more beneficial for students than that of the annual system. To what extent the semester system, as envisaged by policymakers, can help improve the 'employability' of women graduates? Although literature underlines the benefits of the semester system regarding educational achievements (McClure, 2005), no study has specifically discussed woman's academic gains and employment patterns by comparing the education systems in Pakistan.

With increasing higher education enrolments, competition in the job market is also increasing. Graduates realize that solely a degree is not sufficient to secure employment after graduation. The universities have to serve students beyond classroom learning (Teichler, 2007). In this context, the advocates of 'development' have been emphasizing the states to institute 'industry-academia' linkages through public policies (Gul \& Ahmad, 2012). In the case of Pakistan, the HEC has also introduced a policy entitled 'industry-academia' linkages (HEC, 2003; Iqbal, 2007) that encourages all universities to collaborate with relevant segments of the labor market (e.g., industries/organizations/institutions) to integrate academic and research endeavors with emerging market needs. This initiative has addressed several areas of importance, such as student internships, revision of curriculum in the lines of market trends, joint study programs, and joint research projects (Gul \& Ahmad, 2012; Parveen et al., 2011). Literature implies that various research projects lead by 'industry-academia' collaborations, with a special focus on industrial development, produce useful and profit-making results. Later, these collaborations end with a pathway to jobs for graduates (D'Este \& Patel, 2007). Similarly, Knouse and Fontenot (2008) elucidate that internships, short-term training, and mini projects during studies help students to find suitable jobs after graduation. The internship offers several benefits to the intern; it improves their academic performance, improves their time management skills, improves their communication skills, teaches discipline, enhances their self-confidence, improves their decisionmaking abilities, teaches them market-sociology, educates them about work ethics, and reduces anxieties related to employment (Judith, 2009; Lori et al., 2012). Most often selection committees give high preference to candidates with internship backgrounds (Callanan \& Benzing, 2004). Even if interns are not selected in the first round of recruitment, their resumes remain for a longer time in the employment queue (Roever, 2000). By controlling other factors, it can be stated that the involvement of female students in various co-curricular activities during studies can increase their 'employability'.

Throughout the world, recruitment agencies outline selection criteria as per national or firmspecific employment policies. Usually, candidates are first short-listed, and later they are invited to participate in further assessment stages. The academic grades are given special weight throughout the process. For instance, in the case of Pakistan, the Federal Public Service Commission (FPSC) and the Provincial Public Service Commissions (PPSCs) recruit suitable candidates for different jobs. These agencies apply a formula to ascertain a merit list, which converts obtained academic marks into a 30 points scale, and remaining marks are granted based on job-specific tests and interviews. As a result, candidates with high academic grades have a higher likelihood to secure employment (Yousaf \& Hashim, 2012). To find suitable employment, students want to improve their academic grades, especially when they are close to finishing their studies (Klaauw \& Vuuren, 2010). Literature also infers that academic grade depend on study motivation, study efforts, academic goals, self-efficacy, and urge for suitable employment (Credé \& Kuncel, 2008; McKenzie \& Schweitzer, 2010). But despite its importance, several studies have revealed that many students do not pay attention to their studies (Colonna, 2007; Leuven, Oosterbeek, \& Klaauw, 2009) and other factors negatively influence their academic performance, as a result, they do not finish with good grades (Brint \& Cantwell, 2010). Literature also associates academic grades with certain disciplines. Students of 'science and technology' are more conscientious towards studies in comparison to students of 'social sciences' (Brint, Cantwell, \& Saxena, 2012). Existing studies also report that women achieve higher grades than men almost in all disciplines (Conger \& Long, 2010; Kumar \& Debjani, 2013). So, the literature infers that 'ability' and 'above average grades' contribute to improve 'employability' of students after graduation that can help them in the process of a job search. 
Moreover, there is a strong relationship between the aim of higher education and employment. The aim of higher education varies among individuals; it can be the utilization of time, uplifting of social status, and desire to produce earnings, etc. Nevertheless, a woman's position in society changes when she strives for education. If she extends her vision and wishes to utilize her education in the labor market, her chances to have employment increase. In several cases, women have the desire to work, but different social forces limit their progress (Das, 2006; Khan \& Khan, 2009). If suitable employment is the goal of their education, many attempt to achieve their goals and subsequently find employment after graduation (Schomburg \& Teichler, 2006). It means before entering universities, if women spell out academic goals with an employment perspective and try to achieve these goals, their chances to find suitable employment increase. Other competing goals of education confine them within the household to perform caregiving roles (like relatively less educated or illiterate women).

\section{Research Gaps}

While reviewing existing literature, the following shortcomings are underlined. First, several authors assert that higher education does not guarantee women's participation in the labor market (Das, 2006; Hausmann, Tyson, \& Zahidi, 2012), but these studies do not try to capture different aspects of 'learning mechanisms' based on a candidate finds suitable employment after graduation. Second, few studies emphasize that if women seek 'market-oriented' education, it can help them enter the labor market (Estavez-Abe, 2006; Gareth \& Chant, 2009), but these studies limit the concept of 'marketoriented' education only to 'subjects' rather than other aspects of 'learning mechanisms' (e.g. advancement in higher education, participation in co-curricular activities and academic grades, etc.). Third, the literature links recent higher education expansion and women's increasing enrolment with public policies (Farooq, 2011; Ince, 2010). Few of them also study the effects of these reforms on changing academic structure/culture of universities, but do not highlight their implications on women graduates' employment. Lastly, various studies imply that it is women's own choice to work or stay at home after studies, but the literature does not find concrete evidence whether women also associate their aim of higher education to employment. The HEC has introduced several reforms that aim to improve 'employability' of university graduates. Now it is expected that these reforms will not only challenge the gender-based 'educational segregation', but also alter conventional 'learning mechanisms' at universities, which will help improve the 'employability' of women graduates. Thus, the study answers the following research questions:

1. Does changing academic culture at universities help improve 'employability' of women graduates?

2. Does improved 'employability' help women participate in the labor market after graduation?

\section{METHODS AND MATERIAL}

The study adopts survey research methods for data collection. A multistage cluster sampling technique is used for data collection. From Pakistan, the province of Punjab is selected randomly. The selected province is bifurcated into three regions: Southern, Central and Northern Punjab. There are thirty-five districts and from each region, two districts are selected randomly. From each selected district, one urban and one rural union council are selected to reach respondents randomly. One union council comprises 6000-9000 households.

The services of Lady Health Visitors (LHVs) are hired to identify the respondents (women graduates) from selected union councils. LHVs maintain records of all women of reproductive age who live within their jurisdiction. The LHVs are requested to prepare lists of women graduates from universities. For this purpose, the LHVs are also remunerated on a daily basis. A single day of training is arranged with LHVs to acquaint them with data collection techniques, e.g., the listing of respondents, distribution of questionnaires, and collection of questionnaires within their jurisdiction.

Data is collected through a structured questionnaire from women graduates (not-inemployment \& in-employment). The questionnaire is prepared based on past literature including the Beijing Platform of Action 1995, and various ILO conventions. The questionnaire is pre-tested before a final version is released. In the first section of the questionnaire, women graduates are asked various questions relating to their university education. These questions are intended to examine the effects of recently introduced educational policies on the changing 'educational patterns' at universities, which ultimately determine academic achievement. These achievements ascertain their 'employability' that can influence their participation in the labor market. Answers to these questions are obtained in the 
form of predesigned categories. A total of 793 questionnaires are distributed in six districts through LHVs, out of the 594 are completed by respondents. It is observed during editing that 90 questionnaires are completed incorrectly, leaving 504 questionnaires completed correctly - a response rate of $75 \%$.

Bivariate statistical analysis reveals different associations between predictors (independent variables). These relationships fabricate different theoretical explanations that can have further influence on women's employment status. For instance, educational advancement, subject selection, education system, co-curricular activities and degree results have statistical relationships with each other in different directions and magnitudes. However, out of fifteen statistical relationships, one shows a medium effect size i.e., Education System \& Degree Results (.331), and another confirms strong effect sizes i.e., Examination System and Degree Year (.546). These statistical associations are employed as interaction terms in the LRA. For the first interaction term, it is postulated that because the women who graduate under the semester system have obtained high grades in the last university degrees, therefore, their probability to participate in the labor market is high. For the second interaction term, it is hypothesized that because a majority of women has graduated from universities under the semester system after 2002, hence due to their improved employability, their chances to participate in the labor market are high. We use these interaction terms in the Logistic Regression Analysis (LRA).

Finally, we have deployed LRA with (Backward: LR) method. The analysis has been carried out by employing eight predictors and two interaction terms to predict the working status of university-graduate women. To fulfil the preconditions of the LRA, multicollinearity between all predictors is examined. Although the values of Phi test, and Point-biserial Correlation do not exceed from the cut point (0.7), which indicate no multicollinearity between predictors, on the safe side, we have also employed 'Tolerance' and 'Variance Inflation Factor (VIF)' to examine/reconfirm the multicollinearity between predictors. The statistics do not confirm multicollinearity between predictors, because the tolerance values of every predictor are above than 0.1 , and do not exceed from 10 in the case of VIF.

\section{RESULTS}

The findings are summarized in two tables. Table 1 explains the results of the LRA with main effects and interaction terms and table 2 provides an insight into the subject-wise distribution of respondents with respect to their participation in the labor market.

Table 1: Logistic Regression Predicting Women's Participation in the Labor Market after Studies by Main Effects and Interaction Terms (Backward LR)

\begin{tabular}{llllll}
\hline \multicolumn{1}{c}{ Predictors } & B & S.E. & Wald & Sig. & Exp(B) \\
\hline Discipline of Degree & .685 & .198 & 11.930 & .001 & 1.984 \\
Degree Results & .549 & .201 & 7.491 & .006 & 1.732 \\
Year of Degree Completion & -.717 & .337 & 4.540 & .003 & .488 \\
Constant & -4.728 & 1.971 & 5.757 & .016 & .009 \\
\hline
\end{tabular}

The above table explains the results of LRA with main effects and interaction terms, employed to predict the probability of a woman to participate in the labor market after completing her university education. The analysis produces the final model in seven steps. The final model eliminates four main predictors and interaction terms that are non-significant. A test (omnibus) of the full model versus a model with intercept only is statistically significant, $\left(\mathrm{X}^{2}(4, \mathrm{~N}=500)=30.837, \mathrm{p}=.000\right)$. The value of -2 Log Likelihood increases from 624.198 to 633.227 hence the $\mathrm{R}^{2}$ statistics slightly decrease from .104 to .081 between steps 1 to 7 . However, the results do not reflect a significant increase in the overall success rate of the model because it changes very slightly from $62.0 \%$ (at zero) to $62.4 \%$ (final model). But a non-significant value $\left(\mathrm{X}^{2}(4, \mathrm{~N}=500)=6.263, \mathrm{p}=.282\right)$ of the Hosmer and Leme show test indicates that data fit well to the model. The table also indicates the Logistic Regression Coefficients, Standard Error, Wald test, and Odds ratio for each of the predictors. Employing a .05 criterion of statistical significance, from main predictors; education level of women, the discipline of degree, last degree results, and degree completion year have significant effects. The odds ratio for the education level of women indicates that when holding the other three significant variables constant, the odds for labor market participation of the women with an elevated level of education increase 1.303 times than the odds of women with a relatively lower level of education. The odds ratio for the 
discipline of degree indicates that when holding other three significant variables constant, the odds for labor market participation of the women who study various subjects from the 'science \& technology' increase 1.984 times than the odds of women who study different subjects from the 'social sciences or arts and humanities'. The odds ratio for the degree results indicates that when holding other three significant variables constant, the odds for labor market participation of the women who obtain 'first division or CGPA between 3.0-4.0' in the last academic degrees increase 1.732 times than the odds of women who obtain ' 2 nd / 3rd division or CGPA between 1.5-2.99' in the last academic degrees. The odds ratio for the degree completion year indicates that when holding the other three significant variables constant, the odds for labor market participation of the women who graduate from universities after 2002 decrease .488 times than the odd of women who graduate before 2002. Finally, interaction terms do not predict the outcome of the dependent variable.

Table 2: Selected Disciplines, Subjects, and Employment Status of Women Graduates

\begin{tabular}{rlrc}
\hline & \multicolumn{2}{c}{ Explanatory Variables } & \multicolumn{2}{c}{ Response Variables } \\
Not-in-employment
\end{tabular}

The above table [2] informs about the employment status of women graduates with respect to their subject-wise preferences. The table includes information about the top ten subjects studied by the women graduates. The cross-tabulation explains that the women study Business Studies, Chemistry, Mathematics, and Medicine from the 'science \& technology' at priority. They prefer to study Psychology, Economics, and Sociology from the 'social sciences'. And from the 'arts \& humanities', they study English, Education, and Urdu preferably. Moreover, the statistics also infer that the women who study Business Studies, English and Chemistry have a higher tendency to participate in the labor market whereas those who prefer to study Urdu, Education, and Medicine are less likely to prefer paid work after graduation. It is interesting to know that despite studying Medicine, the majority of medical graduates do not enter the labor market.

\section{DISCUSSION}

The inferences reveal that despite their improved level of education, a majority of women is not participating in the labor market after graduation. By controlling broad effects of socio-cultural and political factors, salient aspects of 'educational patterns' enable a few and prevent many of them to join the labor market. Past studies hypothesize that an increase in women's level of education enhances their likelihood to participate in the labor market (Ejaz, 2007; Ince, 2010; Khan \& Khan, 2009). Literature also opposes this claim with the argument that only elevating the level of education does not guarantee women's entry into the labor market (Das, 2006; Morley, 2010; Nelson, 2004). This debate opens a new discourse that extends its focus beyond the 'education level' and encompasses other dimensions of 'educational patterns' that determine women's 'employability' for the labor market. Our results provide an insight into selected 'educational patterns' adopted by women while studying at universities. In statistical analysis, four predictors explain the employment status of women graduates in different directions and magnitudes. The following discussion proceeds according to the initially proposed propositions.

\section{HEC's Policies, Universities' Academic Culture and Employability of Graduates}

In the beginning, it is posited that the HEC's selected reforms will have brought significant changes in the 'learning mechanism' at universities. These changes are supposed to inculcate 'market-oriented' skills among learners to improve their 'employability' for the labor market. We have introduced two variables to test this proposition: 'degree completion year' and the 'education system'. The first 
variable is divided into two categories based on a 'time-point' of 2002. The rationale behind this time point is that the government has introduced various policies in the higher education sector in 2002 (JICA, 2008; Shaukat, 2013), which will have changed the old education system at universities. The second variable is also classified in two education systems; the annual and the semester, where the semester system is a product of new higher education policies. Although new reforms help in reducing gender inequalities in higher education enrolments, to what extent do university-graduate women obtain a benefit from new learning mechanisms to equip themselves with 'market-oriented' skills so that they can enter the labor market after graduation?

The results reveal a change in the attitude of women graduates towards 'educational patterns', when we compare their academic activities and learning priorities after the implementation of new higher education reforms. The analysis divides woman graduates into two categories: graduated before 2002 and after 2002. Most women who have graduated before 2002 has a lack of interest in employment at the time of enrollments, studied various subjects from the 'social sciences, art \& humanities' preferably, and have comparatively lower grades in final degrees. On the other hand, a majority of women who have graduated after 2002, advanced their higher education (M.Phil or PhD), studied 'market-oriented' subjects, participated in co-curricular activities, and obtained relatively better grades in final degrees. These inferences imply that recent women graduates would have not only challenged 'educational segregation' at universities but have also opted for 'learning mechanisms' leading towards improved 'employability' than the earlier group. The distribution of the sample shows that only 9 percent of respondents have obtained university education during the 19752002 periods versus 91 percent who have graduated afterwards.

However, labor market participation trends of the recent group are discouraging compared to the earlier group. It is observed that 46 percent respondents who have obtained their degrees before 2002 are present in the labor market, whereas only 37 percent respondents who have graduated after 2002 have jobs. This variable also contributes to the LRA model significantly. Hence, it is stated that the chances of employment significantly reduce for the women who have graduated from universities after 2002. There can be various explanations for these inferences. We perceive this paradox in the following dimensions. First, although higher education policies have brought an overwhelming majority of women into universities during the last two decades, gender-sensitive policies in the labor market are still missing or are poorly implemented. Thus, the state is responsible for the inadequate participation of women in the labor market after graduation. Second, although data do not support the following assertions, it is presumed that the earlier group more likely has an adequate level of experience or relatively more freedom from household chores or childcare responsibilities; hence the majority is serving as 'paid' employees in the 'formal' sector. Third, job hunting has never been as difficult for them due to their improved academic qualifications, and their smaller size in the population in past. Fourth, the findings endorse the results of (Psacharopoulos \& Patrinos, 2002; Hannum \& Buchmann, 2005) that the mismatch between supply and demand sides also deters women's entry into the labor market. Emerging labor markets may have a narrow breadth. Hence, they cannot absorb recently produced graduates by the universities. Gender bias in the labor market is further impacting this disparity. Therefore, it is concluded that the majority of women who have graduated from universities after 2002, despite their improved 'employability', are deprived of employment opportunities.

These results explain the differences in 'educational patterns' and 'employment trends' of women graduates based on time intervals, but what effects higher education policies have produced on the 'learning mechanism' at universities, is not clear. The following discussion sheds light on this dimension. Solely a temporal analysis is not sufficient to understand differences in the educational and employment patterns of women graduates until we comprehend the mediating factors, which have caused differentiation. It is often questioned whether an educational system offers different skills to learners, which further separate them into employed or unemployed in societies. It has already been discussed that universities are offering education under the annual and the semester systems. Both systems have been producing graduates with various skills and qualities to fuel the national economy. On the recommendations of a committee entitled 'NCES (2005)', universities have shifted their 'academic systems' from the annual to semester systems throughout the country (HEC, 2003; Yousaf \& Hashim, 2012). To what extent has the semester system proved itself as productive specifically for women's employment? 
Our results indicate that all women (earlier group) have studied under the annual system before 2002. The recent group has studied under the semester system, except the graduates of medicine, as medical education has an exemption from this policy (Khan, Biggs, \& Mubbashar, 2011). Women graduates of the annual system have no desire, now of enrolments, to utilize their learning in the labor market. Their response toward co-curricular activities is comparatively discouraging. Most of them do not obtain high grades in the last examinations. Most importantly, many of them do not study 'market-oriented' subjects. On the other hand, those who have graduated under the semester system studied 'market-oriented' subjects. They have shown a keen interest in improving their skills by concentrating on their studies and participating in various co-curricular activities. As a result, they have obtained above-average academic grades in final degrees. These are strong evidence to claim that change in the higher education culture through public policies have caused a change in the attitudes of women toward learning; many of them have moved from 'traditional' to 'market-oriented' educational patterns.

Although these findings imply that education under the semester system makes a significant difference in the skills acquirement process, on the matter of employment, the situation is reversed. The percentage of working women who have studied under the annual system is slightly higher than the semester system graduates. The findings conclude that although women have shown enthusiasm to learn 'market oriented' skills under the semester system, which has helped them improve their 'employability', these achievements could not help them in finding suitable employment after graduation. It seems there is an inconsistency between higher education and employment policies in the country, therefore women are entering universities in large numbers, but they lack employment opportunities after graduation. The outcomes seem a result of inappropriate gender mainstreaming of the policies/programs specifically designed for the labor market. By comparing the time frame and education system, we can observe significant differences in the 'educational patterns' of women graduates. Based on empirical results, the hypothesis is accepted that the public policies in the higher education sector have changed the academic culture at universities. The new culture has introduced new 'learning mechanisms' that have helped female students improve their 'employability' during their studies, but gender-sensitive measures are missing on the part of labor market, which seems the biggest barrier to women's employment after graduation.

\section{Learning Patterns, Employability of Graduates, and Labor Market Participation}

By consulting empirical inferences, this section tests a second hypothesis: improved 'employability' facilitates women's participation in the labor market after graduation. Theoretically, it is posited that there is special 'educational patterns' that help students improve their 'employability' during their studies. To what extent women graduates have adopted 'market oriented' educational patterns to improve their 'employability' at the first instance, and which one enhances their chances to secure employment after graduation? Our inferences shed light on them individually.

Advancement within higher education: Many researchers believe that access to education increases the probability of women to participate in the labor market. Nevertheless, our inferences contradict this assertion. Our results accept this hypothesis partially. The sample of our study comprises women graduates from universities, and a plausible number of these women are not present in the labor market. It infers that university education, counter to expectations, cannot provide a majority of women with employment.

Nevertheless, our inferences also prove another portion of this hypothesis: advancement within higher education can bring women graduates to workplaces (UNESCO, 2012). Universities are offering a variety of academic programs ranging from Bachelor to Doctorate levels in Pakistan (AEPAM, 2011; Qureshi, 2003). The standard duration of these academic programs increases variably, from a minimum of 16 years to a maximum of 21 years, depending on the type of degree. Varying lengths of academic degrees shows that a group of women stays longer in the universities than others. Although most women do not enter the labor market after graduation, our inferences underline that the employment patterns of women graduates differ with respect to their level of academic degrees. It is particularly mentioned here that a valid prediction about women's employment with respect to their academic degrees is a bit complicated. Thus, to make the results simple and more informative, we have introduced a variable: 'completed years of education' in the LRA. Inferences imply that higher years of education increase the likelihood of women graduates to participate in the 
labor market. These inferences imply that women with Bachelor or Master Degrees (16 years of education) have a lower tendency to participate in the labor market as compared to the graduates with above 16 years of education (Double Master, M.Phil, PhD etc.).

Apart from this, when women pursue further education after completing their first academic degrees, our results underline that they also possess various 'academic characteristics' that help them prove their 'employability'. For example, a majority selects subjects by personal preferences, prefers to study subjects from 'science \& technology', participates in co-curricular activities enthusiastically, and obtains high academic grades in final degrees. The study of 'market-oriented' subjects and attainment of high academic grades show a positive influence on their employment status in the LRA. Thus, it can be concluded that these characteristics directly improve 'employability' of women graduates. Hence, this cluster has a higher likelihood to participate in the labor market.

Subject Selection: Many studies claim that women prefer those subjects that lack compatibility with emerging market demands. As a result, these graduates are less likely to be employed by the labor market (Gareth \& Chant, 2009; Morley, 2010a; Nelson, 2004). They are considered better 'homemakers' instead of 'breadwinners' in many societies. To a large extent, our results also endorse these findings, because the results of the LRA indicate that woman graduates who have studied various subjects from 'science \& technology' has a higher tendency towards paid employment as compared to the graduates of 'social sciences, arts \& humanities'. In the lines of Mandel and Shalev's (2009) theory of 'Varieties of Capitalism', Leathwood's (2005) work on 'Woman's Socialization', Chakraborty's (2009) theory of 'Patriarchy' and Spelke's (2005) work on 'Self-determination', our findings also indicate that the functioning of society and the labor market in Pakistan do not differ from rest of the world, where labor markets largely prefer 'market-oriented' graduates without paying attention to existing 'educational segregations' at grass root levels. In Pakistan, a cluster of women who have graduated from universities after 2002, selected 'traditionally-female' subjects, neither participated in co-curricular activities nor obtained high academic grades in final degrees, they are less likely to participate in the labor market.

Our study also answers a relevant question. Is it a personal choice of women or other forces that influence their decisions towards the selection of 'educational patterns'? First of all, autonomy in the subject selection indicates that a woman is adequately empowered. The women who are autonomous on the matter of subject selection, show more interest in studies, adopt different strategies to improve their 'employability', and their chances to enter the labor market are also high (EstévezAbe, 2006; Spelke, 2005). Interestingly, our results reveal that most women graduate practice autonomy on the matter of subject selection. Within this group, if most of them studies various subjects from 'science \& technology', participates in co-curricular activities, obtains higher academic grades, their employment ratio is comparatively higher than others. Thus, it can be concluded that autonomy in subject selection and the selection of subjects from the 'science \& technology' increase the likelihood of women graduates to participate in the labor market in Pakistan (except medicine graduates). It is also imperative to mention here, because a majority of women study 'traditionallyfemale' subjects by their own choice, hence this might explain why their vast majority is out of labor market.

Participation in Co-curricular Activities: Theoretical section has already explained that human resource development is a combination of different skills learning mechanisms. Only focusing on academic activities, the universities cannot impart requisite skills among students sought by the labor market. It is the responsibility of universities to introduce students to contemporary market dynamics and skills before graduation. Thus, by following the HEC's guidelines, almost all universities have been attempting to promote a culture of 'industry-academia' linkages. It is presumed that women graduates, during academic sessions, will have availed maximum benefits from these initiatives, especially by attending various co-curricular activities relevant to their disciplines. There is no doubt that participation in such activities helps students improve their 'employability'. They learn communication, writing, analytical, time management, bureaucratic skills, and professional ethics from these endeavors.

To assess the impact of women's involvement in co-curricular activities on their employment status after graduation, a variable 'participation in co-curricular activities' is included in the LRA. Nevertheless, it does not produce significant effects on the dependent variable. When I calculate the 
results of associations between predictors, it is observed that most women do not participate in cocurricular activities during their studies. When the proportion of those who do not participate in cocurricular activities and those who do during studies are compared, the latter has a higher probability to enter the labor market compared to the former group. Hence, participation in co-curricular activities during studies appears as an important determinant of 'employability' of university graduates. Our results also manifest that women who participate in co-curricular activities also prefer to advance their level of higher education (from BS/Master to M.Phil or PhD levels), select subjects by personal choice, study various subjects from the 'market-oriented' disciplines, and obtain high grades in final degrees. According to the LRA, those with these characteristics have a higher probability to participate in the labor market.

Degree Results: Excellent academic grades are a distinguished characteristic of individuals to compete for employment. Often high-grade receivers distinguish their counterparts both intellectually and professionally in workplaces. Various studies have asserted that women obtain higher grades than men (Conger \& Long, 2010; Khan, et al., 2012). This distinction implies that they would have a relatively better understanding of theoretical and practical concepts pertaining to their disciplines (Kumar \& Debjani, 2013). In the present study, the comparison between genders is not possible because the sample comprises women only. However, it can be examined what impact academic grades have imparted on the employment status of women graduates. In this context, a variable 'final degree result' is introduced in the LRA. Inferences separate the group of women graduates based on their academic grades. Women in this cluster appear more conscious towards their studies, they study subjects from 'market oriented' disciplines, participate in co-curricular activities during their studies, and end up with high academic grades. Most importantly, the results indicate that higher grades receiver women have a higher probability of participation in the labor market. There can be two justifications for these inferences. First, these women have distinguished intellectual abilities, they have outstanding academic achievements since schooling, and they have also maintained this tradition at universities. These characteristics may also have helped them in winning the confidence of employers. Second, the labor market also prefers high-grade earners by anticipating smart and efficient employees during recruitment processes. Moreover, short-listing of candidates for job-related examinations or viva is usually scrutinized based on prior academic grades. High academic grades serve both purposes. It is concluded that high academic grades receiving women have a higher likelihood to participate in the labor market. These inferences guide to construct a proposition that academic characteristics, like the personal choice of subject selection, advancement within higher education, market-oriented education, above-average degree results, and participation in co-curricular activities are mutually inclusive practices. If any characteristic appears in a woman, there is a high probability that she owns others concurrently - leading to improved 'employability' and participation in the labor market.

\section{CONCLUSIONS}

Our findings lead towards two concluding segments. First, solely access to higher education does not guarantee women's employment after graduating from Pakistani universities. These are certain 'educational patterns' that enhance or reduce their probability to enter the labor market. For example, advancement in academic qualifications (double master or doctoral studies), selection of marketoriented disciplines, study-job training, above-average academic grades, and the aim to utilize learned skills in the labor market are main indicators that can improve their 'marketability'. Although the HEC's reforms have played a significant role in improving the academic culture of universities at par with international standards, women seem secondary beneficiaries. The results reveal that studying under an annual or semester system has varying impacts on their 'educational patterns'. Most women who have graduated under the annual system have no aim to join the labor market, have no interest in subjects from 'science \& technology', have less likely to participate in co-curricular activities, and have average grades in last degrees. Nevertheless, despite these deficiencies, a majority is present in the labor market. On the flipside, most woman graduates under the semester system have preferred to study subjects from 'science \& technology', have participated in co-curricular activities, and obtained above-average grades in final degrees. Nonetheless, a majority do not prefer to participate in the labor market, despite having an outstanding 'marketability'.

Overall, a majority of women graduates have shown autonomy on the matter of subject selection, which reflects that cultural stereotype towards their 'educational choices' are being 
challenged today. Nevertheless, sole autonomy on the matter of subject selection does not help many on the matter of employment, but a rational choice in view of emerging market needs can improve their 'marketability' after graduation. Moreover, women have studied Business Studies, Chemistry, Mathematics, and Medicine from the 'science \& technology' preferably, and preferred to study English, Psychology, Economics, Sociology, and Urdu from the 'social sciences, arts \& humanities'. The subjects of Business Studies and Chemistry from the former group, and English and Psychology from the latter group appear highly predictive for women's employment in Pakistan.

Second, the above empirical evidence implies that change in the women's attitudes towards 'educational patterns' can be observed not only with their increased enrollment at universities, but also through changing preferences from 'traditional' to 'market-oriented' higher education. Nonetheless, the miracle of 'reduction in gender gap' in enrollments does not appear in the labor market. Therefore, many women who graduate after 2002 are still excluded from the labor market. It shows that there are serious gaps in the 'gender mainstreaming' of public policies aiming to ensure gender equality in higher education institutions and the labor market. On the part of higher education, the inclusion of 'gender perspective' in the relevant policies serves well, whereas, in the labor market, the situation is still questionable. Thus, my findings support the first proposition that relevant policies have brought a plausible change in the higher education culture where an increasing number of female students are learning 'market-oriented' skills, but results do not support the second proposition because the only access to university education and 'improved employability' do not guarantee their employment after graduation. Our findings are aligned well with Hannum and Buchmann (2005), and Krueger and Lindahl (2001) that the return of education is associated with the ability. The abilities of graduates cannot be measured solely based on years of education, but there is specific 'education patterns' which shape their competencies and enhance their suitability for employment. It is concluded that improved 'marketability' followed by gender-sensitive labor market policies and legislation can help women enter the labor market after graduation, otherwise academic degrees only provide a convenient 'job queue' to employers.

\section{ACKNOWLEDGEMENT}

The data and results have also been discussed in the $\mathrm{PhD}$ thesis of the corresponding author. The thesis has been published with the Shakir Publisher in the form of a monograph, i.e., Tahir, M. W. (2017). Is Higher Education Enough? Explaining Barriers to Women's Employment in Pakistan. Germany: Shakir Publisher. Nevertheless, the corresponding author has an agreement with the publisher that allows publishing research papers out of the already published monograph.

\section{REFERENCES}

Academy of Educational Planning and Management (AEPAM). (2011). Pakistan education statistics 2010-11. Retrieved from http://www.aepam.edu.pk/Files/EducationStatistics/PakistanEducation Statistics2010- 11.pdf on 09.08.2021 at 08:12 am.

Aslam, H. D., Younis, A., Sheik, A. A., Maher, M., \& Abbasi, Z. A. (2012). Analyzing factors affecting students' satisfaction regarding semester system in universities of Pakistan. Journal of American Science, 8(10), 163-170.

Ayalon, H. (2003). Women and men go to university: Mathematical background and gender differences in choice of field in higher education. Sex Roles, 48(5-6), 277-290. doi: 10.1023/A: 1022829522556

Bebbington, D. (2002). Women in science, engineering and technology: A review of the issues. Higher Education Quarterly, 56(4), 360-375. doi: 10.1111/1468-2273.00225

Brint, S., \& Cantwell, A. M. (2010). Undergraduate time use and academic outcomes: Results from the University of California undergraduate experience survey 2006. Teachers College Record, 112(9), 2441-2470.

Brint, S., Cantwell, M. A., \& Saxena, P. (2012). Disciplinary categories, majors, and undergraduate academic experiences: Rethinking Bok's "underachieving colleges"' thesis. Research on Higher Education, 53(1), 1-25. doi:10.1007/s11162-011-9227-2

British Council. (2014). South Asia and higher education revolution and realities in the new economic order. Retrieved from https://www.britishcouncil.org/sites/default/files/gedsas_bc_template.pdf on 06.09.2021 at 20:30 pm. 
Buchmann, C., \& DiPrete, T. A. (2006). The growing female advantage in college completion: The role of family background and academic achievement. American sociological review, 71(4), 515541. doi: $10.1177 / 000312240607100401$

Callanan G., \& Benzing, C. (2004). Assessing the role of internships in the career-oriented employment of graduating college students. Education and Training, 46(2), 82-89. doi:10.1108/00400910410525261

Chakraborty, A. (2009). Determinants of participation in higher education and choice of disciplines: Evidence from urban and rural Indian youth. South Asia Economic Journal, 10(2), 371-402. doi:10.1177/139156140901000205

Colonna, F. (2007). Labour market and schooling choice: Italy vs US. Retrieved from http://www.eief.it/files/2008/01/lab-marktschchoicenov07bis.pdf on 23.08.2021 at 16:20 pm.

Conger, D., \& Long, M. C. (2010). Why are men falling behind? Gender gaps in college performance and persistence. The Annals of the American Academy of Political and Social Science, 627(1), 184-214. doi: 10.1177/0002716209348751

Credé, M., \& Kuncel, N. R. (2008). Study habits, skills, and attitudes: The third pillar supporting collegiate academic performance. Perspectives on Psychological Science, 3(6), 425-453. doi: 10.1111/j.1745-6924.2008.00089.x

D'Este, P., \& Patel, P. (2007). University industry linkage in UK: What are the factors underlying the variety of interactions with industry? Research Policy, 36(9), 1295-313. doi:10.1016/j.respol.2007.05.002

Das, M. B. (2006, June 1). Do traditional axes of exclusion affect labor market outcomes in India? Retrieved from http://documents.worldbank.org/curated/en/195941468034790110/pdf/369630sdp970web .pdf on 01.09.2021 at 10:45 am.

Ejaz, M. (2007). Determinants of female labor force participation in Pakistan an empirical analysis of PSLM (2004-05) Micro Data. The Lahore Journal of Economics, Special Edition, 203-235.

Estavez-Abe, M. (2006). Gendering the varieties of capitalism: A study of occupational segregation by sex in advanced industrial societies. World Politics, 59(1), 142-175. doi: 10.1353/wp.2007.0016

Farooq, S. (2011). Mismatch between education and occupation. The Pakistan Development Review, 50(4/2), 531-553.

Gareth, A. J., \& Chant, S. (2009). Globalising initiatives for gender equality and poverty reduction: Exploring 'failure' with reference to education and work among urban youth in the Gambia and Ghana. Geoforum, 40(2), 184-196. doi:10.1016/j.geoforum.2008.07.008

Gul, A., \& Ahmad, A. (2012). Perspectives of academia-industrial linkage in Pakistan: An Insight Story. Science, Technology and Development, 31(2), 175-182.

Hannum, E., \& Buchmann, C. (2005). Global educational expansion and socio-economic development: An assessment of findings from the social sciences. World Development, 33(3), 333-354. doi:10.1016/j.worlddev.2004.10.001

Hausmann, R., Tyson, D. L., \& Zahidi, S. (2012). The global gender gap report 2012. Retrieved from http://www3.weforum.org/docs/WEF_GenderGap_Report_2012.pdf on 12.08.2021 at 10:10 am.

Higher Education Commission (HEC). (2003). Annual report for 2002-03. Retrieved from http://www.hec.gov.pk/MediaPublication/NewsViews/Documents/780_Annual _Report_2002_3.pdf on 03.08.2021 at 10:00 am.

Hill, C., Corbett, C., \& St Rose, A. (2010). Why so few? Women in science, technology, engineering, and mathematics. Washington, DC: American Association of University Women.

Ince, M. (2010). How the education affects female labour force? Empirical evidence from Turkey. Procedia Social and Behavioral Sciences, 2(2), 634-639. doi:10.1016/j.sbspro.2010.03.076

Inglehart, R., \& Norris, P. (2003). Rising tide: Gender equality and cultural change around the world. New York: Cambridge University Press.

Iqbal, Y. (2007). A stone can be turned into gold but how? Journal of Pakistan Materials Society, $1(1), 28-30$.

Jadoon, J. I., Jabeen, N., \& Zeba, F. (2012). Towards effective implementation of semester system in Pakistan: Lessons from Punjab university [paper presentation]. 2nd International Conference on Assessing Quality in Higher Education, Lahore, Pakistan. http://www.icaqhe2010.org/ 
Japan International Cooperation Agency (JICA). (2008). Pakistan: Country gender profile. Retrieved from http://www.jica.go.jp/pakistan/english/office/ others/pdf/CGP_01.pdf on 10.10.2021 at 18:20 pm.

Judith, M. (2009). Internships: Effective work integrated learning for law students. Asia- Pacific Journal of Cooperative Education, 10(3), 229-240.

Khan, A. H., Nawaz, M. M., Aleem, M., \& Hamed, W. (2012). Impact of job satisfaction on employee performance: An empirical study of autonomous medical institutions of Pakistan. African Journal of Business Management, 6(7), 2697-2705

Khan, R. E. A. \& Khan, T. (2009). Labour force participation of married women in Punjab (Pakistan). Journal of Economic and Social Research, 11(2), 77-106.

Khan, S. J., Biggs, S. J., \& Mubbashar, H. M. (2011). Medical education evaluation techniques in Punjab, Pakistan: Eight years of reforms in health professional education. Journal of Ayub Medical College, 23(1), 154-158.

Khattak, I. Z., Ali, M., Khan, A., \& Khan, S. (2011). A study of English teachers and students' perception about the differences between annual and semester system of education at postgraduate level in Mardan. Procedia Social and Behavioral Sciences 15, 1639-1643. doi:10.1016/j.sbspro.2011.03.34

Klaauw, D. V. B., \& Vuuren, V. A. (2010). Job search and academic achievement. European Economic Review, 54(2), 294-316. doi:10.1016/j.euroecorev.2009.07.001

Knouse, B. S. \& Fontenot, G. (2008). Benefits of the business college internship: A research review. Journal of employment counseling, 45(2), 61-66. doi:10.1002/j.2161-1920.2008

Krueger, B. A., \& Lindahl, M. (2001). Education for growth: Why and for whom? Journal of Economic Literature, XXXIX, 1101-1136. doi: 10.3386/w7591

Kumar, A. D., \& Debjani, S. (2013). Women and gender stereotyping in higher education: A case study of Vidyasagar University post-graduates. International Journal of Research Studies in Education, 2(1), 75-90. doi: 10.5861/ijrse.2012.107

Leathwood, C. (2005). Treat me as a human being - don't look at me as a woman: Femininities and professional identities in further education. Gender and Education, 17(4), 387-409. doi: 10.1080/09540250500145221

Leuven, E., Oosterbeek, H., \& Klaauw, B., (2009). The effects of financial rewards on students' achievements: Evidence from a randomized experiment. Journal of the European Economic Association, 8(6), 1243-1265. doi: 10.1111/j.1542-4774.2010.tb00554.x

Leuze, K. (2010). Smooth path or long and winding road? How institutions shape the transition from higher education to work. Germany: Budrich UniPress Ltd.

Lori, S., Lawrence, F., Nancy, B., Heather, C., Denise, G., David, F., \& Verda, P. (2012). Lessons learned from experiential learning: What do students learn from a practicum/internship? International Journal of Teaching and Learning in Higher Education, 24(3), 325-334.

Mandel, H. \& Shalev, M. (2009). Gender, class and varieties of capitalism. Social Politics, 16(2), 161181. doi:10.1093/sp/jxp00

McClure, J. E. (2005). Plus/minus grading and motivation: An empirical study of student choice and performance. Assessment \& Evaluation in Higher Education, 30(6), 571-579. doi:10.1080/02602930500260605

McKenzie, K., \& Schweitzer, R. (2010). Who succeeds at university? Factors predicting academic performance in first year Australian university students. Higher Education Research \& Development, 20(1), 21-33. doi:10.1080/07924360120043621

Morley, L. (2010). Gender equity in higher education: Challenges and celebrations. International $\begin{array}{lllll}\text { Encyclopedia of Education (3rd ed.), } & \text { pp. }\end{array}$ http://www.sciencedirect.com/science/article/pii/B978008044894700110X

Nelson, C. (2004). UAE national women at work in the private sector: Conditions and constraints. Retrieved from http://www.zu.ac.ae/infoasis/modules/mod8/business/documents/uaenationalwomenatwor $\quad \mathrm{k}$ intheprivatesector.pdf on 02.09.2021 at 10:30 am.

Parveen, A., Rashid, K., Iqbal, Z. M., \& Khan, S. (2011). System and reforms of higher education in Pakistan. International Journal of Business and Social Science, 2(20), 260- 267.

Porter, S. R., \& Umbach, P. D. (2006). College major choice: An analysis of person- environment fit. Research in Higher Education, 47(4), 429-449. doi:10.1007/s11162-005-9002-3 
Psacharopoulos, G., \& Patrinos, H. (2002, September 30). Returns to investment in education: A further update. Retrieved from https://ssrn.com/abstract=1273483 on 15.10 .2021 at $14: 19 \mathrm{pm}$.

Qureshi, S. (2003). Pakistan: Education and gender policy girl's education: A lifeline to development. Retrieved from http://www.humanitarianlibrary.org/sites/default/files/2014/02/qureshi.pdf on 25.09.2021 at 13:12 pm.

Roever, C. (2000). Mead corporation's creative approach to internships: Success in a unionized manufacturing plant. Business Communication Quarterly, 63(1), 90-100.

Schomburg, H., \& Teichler, U. (2006). Higher education and graduate employment in Europe. Results of graduate surveys from 12 countries. Netherlands: Springer.

Shah, S. (2010). Re-thinking educational leadership: Exploring the impact of cultural and belief systems. International Journal of Leadership in Education, 13(1), 27-44. doi: $10.1080 / 13603120903244879$

Shaukat, R. (2013). A qualitative investigation of an educational reform initiative in Pakistan (Doctoral Thesis). Faculty of Education, University of Ottawa, Canada. Retrieved from https://www.ruor.uottawa.ca/bitstream/10393/23695/1/Shaukat_Rumaisa_2013_thesis.pd f on 21.09.2021 at 10:42 am.

Spelke, E. S. (2005). Sex differences in intrinsic aptitude for mathematics and science? A critical review. American Psychologist, 60(9), 950-958. doi:10.1037/0003-066X.60.9.950

Stanfors, M. (2006). Educational segregation and the meaning of education to women in twentieth century Sweden. XIV International Economic History Congress, Helsinki, Finland. http://www.helsinki.fi/iehc2006/papers1/Stanfors.pdf.

Stier, H., \& Yaish, M. (2008). The determinants of women's employment dynamics: The case of Israeli women. European Sociological Review, 24(3), 363-377. doi: 10.1093/esr/jen010

Teichler, U. (2007). Does higher education matter? Lessons from a comparative graduate survey. European Journal of Education, 42(1), 11-34. doi:10.1111/j.1465- 3435.2007.00287.x

UNESCO Institute of Statistics. (2015). Women in science. Retrieved from http://uis.unesco.org/en/topic/women-science on 16.09.2021 at 13:15 pm.

UNESCO. (2012). World atlas of gender equality in education. Retrieved from http://www.uis. unesco.org/Education/Documents/unesco-world-atlas-gender-education-2012.pdf on 10.08.2021 at 06:00 $\mathrm{pm}$.

. (2020). A new generation: 25 years of efforts for gender equality in education. Retrieved from https://en.unesco.org/gem-report/2020genderreport on 13.10.2021 at 15:25 pm.

Yousaf, A., \& Hashim, M. (2012). A case study of annual and semester systems of examination on Government College of Management Sciences, Peshawar, Pakistan. International Journal of Academic Research in Business and Social Sciences, 2(9), 53- 73. 